\title{
The effect of daily consumption of coconut fat and soya-bean fat on plasma lipids and lipoproteins of young normolipidaemic men
}

\author{
BY SHANTHI MENDIS ${ }^{1,2}$ AND RAVI KUMARASUNDERA M ${ }^{2}$ \\ ${ }^{1}$ Department of Medicine, Faculty of Medicine, Peradeniya, Sri Lanka and ${ }^{2}$ Institute of \\ Fundamental Studies, 380/72 Bauddhalolea Mawatha, Colombo 7, Sri Lanka
}

(Received 9 June 1989 - Accepted 22 November 1989)

\begin{abstract}
The present paper reports the influence on plasma lipids of isoenergetic diets containing $30 \%$ of energy as fat, with a polyunsaturated: saturated fat ratio of $4 \cdot 00$ or $0 \cdot 25$, consumed for 8 weeks by twenty-five young normolipidaemic males. Approximately $70 \%$ of the fat energy was provided by the test fats: soyabean fat and coconut fat. During the soya-bean-fat-eating period the total plasma cholesterol level fell significantly compared with baseline values $(P<0-001)$ and during the coconut-fat-eating phase total plasma cholesterol level increased significantly compared with the soya-bean-eating period $(P<0.001)$. On the soya-bean-fat diet, high-density-lipoprotein (HDL)-cholesterol decreased by $15 \%$ (range 6-35\%) and plasma triacylglycerols decreased by $25 \%$ (range 13-37\%). Results of the present study show that even when the proportion of total fat in the diet is low, a high intake of linoleic acid lowers both total plasma cholesterol and HDL-cholesterol, while a high intake of saturated fat elevates both these lipid fractions. Application of regression formulas to the present findings indicates that short-chain saturated fatty acids have a neutral effect on serum cholesterol.
\end{abstract}

Dietary fat: Plasma lipids: Lipoproteins

Recent studies in the UK suggest that atherogenesis is either accelerated or premature, or both, in Southern Asians compared with white populations. (Hughes et al. 1989). Coronary heart disease tends to be low in populations consuming high-carbohydrate, low-fat diets (Shaper et al. 1974). Although the habitual diet of Sri Lankans is high in carbohydrate, and fat contributes only $27 \%$ of total energy, coronary heart disease is the leading cause of mortality and morbidity in middle-aged men in Sri Lanka (Shaper et al. 1974; Registrar General's Department, Department of Census and Statistics, 1984). Among the different hypotheses put forward to explain this high incidence of coronary heart disease is the regular intake of relatively high quantities of saturated fat in the Sri Lankan diet (Shaper et al. 1974). As much as $80 \%$ of the fat content of the habitual Sri Lankan diet consists of coconut fat (CF), which is a saturated fat (Wickramanayake \& Panabokke, 1961).

Vascular disease has been reported to be uncommon in Polynesian Islanders who obtain 34-63\% of their food energy from CF (Prior et al. 1981). However, unlike the habitual Sri Lankan diet, fish is the chief source of protein in the diet of Polynesians and fish oil fatty acids are likely to exert a favourable influence on the metabolism of lipids in this population.

Modifications of the Sri Lankan diet which would alter serum lipids and lipoproteins to profiles that are less likely to promote atherosclerosis would be beneficial. Therefore, it was felt necessary to investigate the effects of replacing CF in the habitual Sri Lankan diet with a relatively cheap and readily available polyunsaturated fat (PUSF) such as soya-bean fat. Most human experiments carried out to investigate the effect of saturated fat on plasma lipids have used lard, butter or cocoa fat. The new studies which have used $\mathrm{CF}$, have used it in combination with other saturated fats. The activity of CF has, therefore, not been 
adequately tested. Studies investigating the effects of replacing saturated fats in diets with PUSF have used either maize-oil or safflower-oil. Both these fats are expensive and not readily available to Sri Lankans. Moreover, the cholesterol content, carbohydrate type and quantity, and the fibre content of the experimental diets do not resemble the composition of the habitual Sri Lankan diet. The aim of the present study was to define the effects of replacing CF in the Sri Lankan diet with soya-bean fat on fasting plasma lipids of healthy normolipidaemic men.

\section{MATERIALS AND METHODS}

\section{Subjects}

Twenty-five healthy young adults, 20-26 years of age, participated in the study. They were volunteers from among the prison inmates of the Pallekalle Open Prison Camp, Pallekalle, Sri Lanka. All subjects were within $2 \%$ of normal body-weight and none of the subjects deviated more than $3 \%$ from their baseline (day 1) weight throughout the study. Physical activity was constant and none of the subjects received any medications during the study period.

\section{Experimental design}

The study was divided into two feeding periods of 8 weeks each, a period sufficient to establish the effect of each diet on plasma lipids and lipoproteins. In between the two periods there was a wash-out period of 3 weeks to allow the effects of the preceding test diet to dissipate and plasma lipids and lipoproteins to return to baseline levels. It also provided subjects relief from the difficulties of adhering to the test diet procedures.

\section{Diets}

The experimental diets consisted of foods containing one of the two fats under investigation (CF and soya-bean fat) for lunch and supper, and low-fat, high-carbohydrate foods for breakfast. Standard menus for fourteen different meals over $7 \mathrm{~d}$ were prepared and these meals were served in consecutive cycles every week. Both dietary regimens were isoenergetic. Foods chosen for the main meals were rice, lean meat, fish, poultry, bread, potatoes, dahl and green vegetables. The compositions (mean daily intakes) of the diets are shown in Table 1 . Approximately $70 \%$ of the fat energy was from the test fats. The non-study fats (approximately $30 \%$ of the total fat) were from meat, fish, poultry, vegetables and grains. Cheese, butter and alcoholic beverages were not allowed. All meals were prepared in the prison kitchen and food from outside was not allowed. Adherence to the test diets was judged to be good on the basis of regular interviews with the prison officers and self report.

\section{Biochemical measurements}

Fasting blood samples were drawn at the beginning and at the end of each dietary period for measurement of plasma total cholesterol (TC), triacylglycerol (TG) and high-densitylipoprotein-cholesterol (HDL-C). In the last 2 weeks of each dietary period, two successive measurements of TC and TG were carried out to determine whether the lipid changes were established. The average of these two values was used to evaluate the final lipid change. TC and TG concentrations were determined by enzymic methods (Bucolo \& David, 1973; Siedel et al. 1981). The inter- and intra-assay coefficients of the TC assay were both $<2.5 \%$. The inter- and intra-assay coefficients of the TG assay were 3.5 and $<2.0 \%$ respectively. HDL-C was measured by selective precipitation with dextran sulphate and magnesium chloride (Warnick et al. 1982). The inter- and intra-assay coefficients were both $<2.5 \%$. Plasma low-density-lipoprotein-cholesterol (LDL-C) was calculated by the method of Friedwald et al. (1972). 
Table 1. Mean composition of the diets (mean daily intake)

\begin{tabular}{|c|c|c|}
\hline Dietary fat... & Soya-bean-fat & Coconut fat \\
\hline Energy $(\mathrm{kJ})$ & 10020 & 10150 \\
\hline (kcal) & 2395 & 2425 \\
\hline Protein $(\mathrm{g})$ & 85 & 84 \\
\hline Fat $(\mathrm{g})$ & 78 & 81 \\
\hline Carbohydrates (g) & 350 & 359 \\
\hline Cholesterol (mg) & $250 \cdot 0$ & $250 \cdot 0$ \\
\hline$P: S$ ratio & $4 \cdot 0$ & 0.25 \\
\hline
\end{tabular}

$\mathrm{P}: \mathrm{S}$, polyunsaturated : saturated fat.

\section{Ethical considerations}

The study was approved by an independent ethical committee of the Institute of Fundamental Studies. The nature, requirements, implications and potential hazards of the study were explained to sixty-two men from two dormitories in the prison camp. Forty-five individuals volunteered for the study, of which twenty-five were selected to participate. Written consent was given by every participant. All of them had complete freedom to opt out of the study group during the course of the study.

\section{Statistical methods}

Comparison of the results obtained were carried out using Student's $t$ test for paired values.

\section{RESULTS}

The effects of the two diets on plasma lipids and lipoproteins are shown in Table 2. All men showed a reduction of plasma TC on the soya-bean-fat diet; the mean reduction was $21 \%$ (range $10-35 \%$ ). The mean plasma TC fell from 4.64 (SD 0.37 ) to 3.68 (SD 0.42$) \mathrm{mmol} / 1(P$ $<0.001$ ). All subjects showed a decrease in plasma TG on the soya-bean-fat diet (mean decrease $25 \%$; range $13-37 \%$ ). The mean plasma TG fell from 1.42 (SD 0.44) to 1.06 (SD $0.42) \mathrm{mmol} / 1(P<0.01)$. LDL-C fell during the period on the soya-bean-fat diet, by an average of $23 \%$ (range $5-45 \%, P<0.001$ ). The soya-bean-fat diet also lowered HDL-C. The mean reduction was $15 \%$ (range $6-35 \%, P<0.05$ ). Reciprocal changes were seen when $\mathrm{CF}$ was re-introduced. The lipids and lipoproteins increased to values which were no longer significantly different from the baseline values.

\section{DISCUSSION}

The results of this investigation are in agreement with several metabolic studies that have presented evidence that saturated fats per se, increase the concentrations of plasma TC, and PUSF lower plasma TC in man (Hegsted et al. 1965; Keys et al. 1965; Schafer et al. 1981). Controlled experiments carried out under metabolic ward conditions have shown a relationship between concentrations of dietary fat and cholesterol, and blood cholesterol. Regression formulas based on these studies have been established (Jacobs et al. 1979). The regression equations of Keys et al. (1965): $\Delta$ cholesterol $=1.35(2 \Delta \mathrm{S}-\Delta \mathrm{P})$ and of Hegsted et al. (1965): $\Delta$ cholesterol $=2 \cdot 32(\Delta \mathrm{S}-1 \cdot 3 \Delta \mathrm{P})$ were applied to the data, where $\mathrm{S}$ and $\mathrm{P}$ represent the amounts of saturated $(S)$ and polyunsaturated $(P)$ fats as percentages of the energy content of the diet. The increase in plasma cholesterol on the CF diet compared with the soya-bean-fat diet predicted by the Keys et al. (1965) formula $(1.34 \mathrm{mmol} / \mathrm{l})$ is higher 
Table 2. Concentrations of plasma lipids and lipoproteins during daily consumption of soya-bean fat or coconut fat by healthy young men

(Mean values and standard deviations)

\begin{tabular}{|c|c|c|c|c|c|c|}
\hline \multirow[t]{2}{*}{ Experimental period $\$ \ldots$} & \multicolumn{2}{|c|}{ Baseline } & \multicolumn{2}{|c|}{ Soya-bean fat } & \multicolumn{2}{|c|}{ Coconut fat } \\
\hline & Mean & SD & Mean & SD & Mean & SD \\
\hline Cholesterol (mmol/1) & $4 \cdot 64$ & $0 \cdot 37$ & $3 \cdot 68 * * *$ & $0 \cdot 42$ & $4 \cdot 61+t+$ & 0.39 \\
\hline Triacylglycerol (mmol/l) & $1 \cdot 42$ & 0.44 & $1 \cdot 06^{* *}$ & 0.42 & 1.45 & 0.41 \\
\hline $\mathrm{HDL}-\mathrm{C}(\mathrm{mmol} / \mathrm{l})$ & $1 \cdot 10$ & $0 \cdot 25$ & $0 \cdot 94^{*}$ & $0 \cdot 26$ & $1 \cdot 14$ & $0-27$ \\
\hline $\mathrm{LDL}-\mathrm{C}(\mathrm{mmol} / \mathrm{l})$ & $2 \cdot 95$ & $0 \cdot 43$ & $2 \cdot 27^{* * *}$ & $0 \cdot 36$ & $2 \cdot 84$ & $0-37$ \\
\hline
\end{tabular}

HDL-C, high-density-lipoprotein cholesterol; LDL-C, low-density-lipoprotein cholesterol.

Mean values were signifcantly different from baseline values: ${ }^{*} P<0.05,{ }^{* *} P<0.01, * * * P<0.001$.

Mean values were significantly different from soya-bean fat values; $\dagger+\dagger P<0.001$.

$\ddagger$ For details, see p. 548 and Table 1 .

Table 3. Fatty acid composition of the food fats ( $\mathrm{g}$ fatty acids $/ 100 \mathrm{~g}$ total fatty acids)

\begin{tabular}{ccc}
$\begin{array}{c}\text { Fatty } \\
\text { acid }\end{array}$ & $\begin{array}{c}\text { Coconut } \\
\text { fat }\end{array}$ & $\begin{array}{c}\text { Soya-bean } \\
\text { fat }\end{array}$ \\
$8: 0$ & $10 \cdot 1$ & $0 \cdot 0$ \\
$10: 0$ & $6 \cdot 6$ & $0 \cdot 0$ \\
$12: 0$ & $45 \cdot 8$ & $0 \cdot 0$ \\
$14: 0$ & $18 \cdot 4$ & $0 \cdot 1$ \\
$16: 0$ & $8 \cdot 0$ & $10 \cdot 7$ \\
$16: 1$ & Trace & $0 \cdot 1$ \\
$17: 0$ & Trace & $0 \cdot 1$ \\
$18: 0$ & $2 \cdot 4$ & $3 \cdot 8$ \\
$18: 1$ & $6 \cdot 0$ & $23 \cdot 0$ \\
$18: 2$ & $1 \cdot 7$ & $52 \cdot 4$ \\
$18: 3$ & 0.0 & 8.9 \\
$20: 0$ & 0.0 & $0 \cdot 6$ \\
$22: 0$ & 0.0 & 0.4 \\
\hline
\end{tabular}

than the observed values of $0.93 \mathrm{mmol} / \mathrm{l}$. The results predicted by the Hegsted et al. (1965) formula $(1.13 \mathrm{mmol} / \mathrm{l})$, is also higher than the observed value. In the modified equation of Keys et al. $(1974): \Delta$ cholesterol $=1 \cdot 2(2 \Delta S-1 \cdot 3 \Delta \mathrm{P})$, where $\mathrm{S}$ represents the proportion of saturated fatty acids containing twelve or more carbon atoms. This formula is based on the hypothesis that saturated fatty acids containing fewer than twelve $\mathrm{C}$ atoms have little or no effect on serum cholesterol. In view of the relatively high proportion of short-chain fatty acids in CF (Table 3), the rise in serum cholesterol predicted by the modified Keys et al. (1965) formula was calculated. When this formula is applied to our data there is no significant discrepancy between the predicted value $(0.94 \mathrm{mmol} / 1)$ and the observed value $(0.93 \mathrm{mmol} / 1)$. These observations support the hypothesis that short-chain saturated fatty acids in the diet have a neutral effect on serum cholesterol.

Under specific experimental conditions the cholesterol-elevating effect of saturated fats has been chiefly attributed to their myristic acid (14:0) component (Hegsted et al. 1965). The high myristic acid content of CF (Table 3) is likely to be an important factor in the setting of blood cholesterol values in the CF phase of the study.

The effect of saturated fats on plasma TG have been studied by several investigators who have reached different conclusions. The results of the present study are in agreement with 
the findings of Wilson et al. (1971), Chait et al. (1974), Shepherd et al. (1978) and Becker et al. (1983) of a reduction of plasma TG with PUSF. However, Mattson \& Grundy (1985) and Reiser et al. (1985) found no effect of PUSF on plasma TG. Chait et al. (1974) reported a correlation between the magnitude of the fall in TG level induced by the PUSF diet and the TC concentration during the saturated fat period. This correlation was not found in the present study. In some of these studies (Wilson et al. 1971), the type of fat as well as the type and intake of carbohydrate were different in the two study periods. These changes can contribute to the fall in TG. In the present study, the intake and composition of carbohydrate was the same throughout the study. Therefore, the reduction in plasma $\mathrm{TG}$ can be attributed to the reduction in $\mathrm{CF}$ intake.

The effect of PUSF on HDL-C is controversial. Some reports (Shepherd et al. 1978; Craig et al. 1980; Schafer et al. 1981), show that HDL-C decreases on a PUSF diet, while others report no change (Chait et al. 1974; Schwandt et al. 1982; Becker et al. 1983). On the other hand, Von Lossonezy et al. (1978) and Shore et al. (1981) have reported an increase in HDL-C on a PUSF diet. In the present study the PUSF diet with a P:S ratio of 4 lowered the HDL-C by an average of $15 \%$. Reciprocal changes took place when the $\mathrm{CF}$ diet (P:S ratio $0 \cdot 25)$ was re-introduced. Comparing the effects of a $\mathrm{P}: \mathrm{S}$ ratio of $0.4 v$. $4 \cdot 0$, in the latter case Shepherd et al. (1978) reported a $33 \%$ reduction in HDL-C in the four subjects in their study.

The response of HDL-C appears to be related to the $\mathrm{P}: \mathrm{S}$ ratio of the diet. Schwandt et al. (1982) assessed the effect of a diet with a $P: S$ ratio of 1 with a $P: S$ ratio of $0 \cdot 3$ on plasma lipoproteins. In their study $37 \%$ of the energy was provided by fat. The diet with a P:S ratio of 1 effectively lowered LDL-C without affecting HDL-C. There was also no significant change in the production of thromboxane $\mathrm{B}$ on the two diets (results not presented).

The replacement of CF with soya-bean fat in the habitual diet of healthy normolipidaemic Sri Lankan males caused a specific fall in plasma TC and TG. However, this may not be the best dietary modification for prevention of coronary heart disease in Sri Lankans. The undoubted hypocholesterolaemic effect of soya-bean fat with its implied benefits must be weighed against the potentially harmful reduction of HDL-C. The mean plasma HDL-C concentrations of Sri Lankans have been found to be low compared with Caucasians (Mendis \& Read, 1984). This may be due to the low fat and high complex carbohydrate content of the diet (Mensink \& Katan, 1987). Therefore, further reduction of HDL-C as a result of replacement of CF with PUSF may have undesirable effects. However, diets with higher P:S ratios have been shown to have no effect on HDL-C (Schwandt et al. 1982). Further studies to determine the optimum content of PUSF in the Sri Lankan diet are needed.

The authors are indebted to Professor Cyril Ponnamperuma, Director, Institute of Fundamental Studies, Sri Lanka for his help throughout the study. The assistance of the Superintendent and the officers of the Pallekale Prison Camp is gratefully acknowledged. They also thank Mr Harsha Gamage and Mr Nihal Bandara for their help in conducting this study and the volunteers for their interest and cooperation.

\section{REFERENCES}

Becker, N., Illingworth, R., Alaupovic, P., Connor, W. E. \& Sundberg, E. E. (1983). Effects of saturated, monounsaturated, and $\omega-6$ polyunsaturated fatty acids on plasma lipids, lipoproteins and apoproteins in humans. American Joumal of Clinical Nutrition 37, 355-360.

Bucolo, G. \& David, M. (1973). Quantitative determination of serum triglycerides by enzymes. Clinical Chemistry 19, 476-482. 
Chait, A., Onitiri, A., Nichol', A., Rabaya, E., Jeffrey, D. \& Lewis, B. (1974). Reduction of serum triglyceride level by polyunsaturated fat. Atherosclerosis 20, 347-364.

Craig, I. H., Phillips, P. J., Lloyd, J. V., Watts, S., Bracken, A. \& Read, R. (1980). Effects of modified fat diets on LDL/HDL ratio. Lancet ii, 799.

Friedwald, W. T., Levy, R. I. \& Fredrickson, D. S. (1972). Estimation of plasma low density lipoprotein concentration without use of the preparative ultracentrifuge. Clinical Chemistry 18, 499-502.

Hegsted, D. M., McGrandy, R. B. \& Myers, M. L. (1965). Quantitative effects of dietary fat on serum cholesterol in man. American Journal of Clinical Nutrition 27, 281-295.

Hughes, L. D., Raval, U. \& Raftery, E. B. (1989). First myocardial infarctions in Asian and white men. British Medical Journal 298, 1345i-1350.

Jacobs, D. R., Anderson, J. T. \& Blackburn, H. (1979). Diet and serum cholesterol. Do zero correlations negate the relationship? American Journal of Epidemiology 110, 77-87.

Keys, A., Anderson, J. T. \& Grande, F. (1965). Serum cholesterol response to changes in the diet. Metabolism 14, $747-787$.

Keys, A., Grande, F. \& Anderson, J. T. (1974). Bias and misrepresentation revisited: perspective on saturated fat. American Journal of Clinical Nutrition 27, 188-212.

Mattson, F. H. \& Grundy, S. M. (1985). Comparison of effects of dietary saturated, monounsaturated and polyunsaturated fatty acids on plasma lipids and lipoproteins in man. Journal of Lipid Research 26, $194-202$.

Mendis, S. \& Read, A. E. (1984). Serum cholesterol concentration and serum high density lipoprotein concentration in children and adolescents. Proceedings of the Sri Lanka Association for the Advancement of Science 40, 2-3.

Mensink, R. P. \& Katan, M. B. (1987). Effects of monounsaturated fatty acids versus complex carbohydrates on high density lipoproteins in healthy men and women. Lancet i, 122-125.

Prior, 1. A., Davidson, F., Salmond, C. E. \& Czochanska, Z. (1981). Cholesterol, coconuts and diet on Polynesians atolls: a natural experiment: the Pukapuka and Tokelau island studies. American Journal of Clinical Nutrition 34, 1552-1561.

Registrar General's Departrnent, Department of Census and Statistics (1984). Mortality and Morbidity Statistics. Colombo, Sri Lanka: Ministry of Plan Implementation.

Reiser, R., Probstfield, J. L., Silvers, A., Scott, L. W., Shorny, M. L., Wood, R. D., O'Brien, B. C., Gotto, A. M. \& Insull, W. Jr (1985). Plasma lipid and lipoprotein response of humans to beef fat, coconut oil and sunflower oil. American Journal of Clinical Nutrition 42, 190-197.

Schafer, E. J., Levy, R. J., Ernest, N. D., Van Sant, F. D. \& Brewer, H. B. (1981). The effects of low cholesterol, high polyunsaturated fat and low fat diets on plasma lipids and lipoprotein cholesterol levels in normal and hypercholesterolaemic subjects. American Journal of Clinical Nutrition 34, 1758.

Schwandt, P., Janetschek, P. \& Weisweiler, P. (1982). High density lipoproteins unaffected by dietary fat modification. Atherosclerosis 44, 9-17.

Shaper, A. G., Hutt, M. S. R. \& Fejfar, Z. (editors) (1974). Cardiovascular Disease in the Tropics. London: British Medical Association.

Shepherd, J., Packard, C. J., Gotto, A. M. \& Taunton, O. D. (1978). Effects of dietary saturated and polyunsaturated fat on the metabolism of apolipoproteins A-I and B. Clinica Chimica Acta 87, 395-404.

Shore, V. G., Krauss, R. M., Butterfield, G., Deshaies, Y. \& Lindgren, F. T. (1981). Effects of dietary polyunsaturated : saturated fat ratio of human serum lipoproteins. Arteriosclerosis 1, 386a/Abstr.

Siedel, J., Schlumberger, H. \& Klose, S. (1981). Improved reagent for the enzymatic determination of serum cholesterol. Journal of Clinical Chemistry and Clinical Biochemistry 19, 838-839.

Von Lossonezy, T. O., Ruiter, A., Bronsgeest-Schoute, H. C., Van Gent, C. M. \& Hermus, R. J. J. (1978). The effect of a fish diet on serum lipids in healthy human subjects. American Journal of Clinical Nutrition 31, $1340-1346$.

Warnick, G. R, Benderson, J. \& Albers, J. J. (1982). Dextran-sulfate-Mg precipitation procedure for quantitation of high density lipoprotein cholesterol. Clinical Chemistry 28, 1379-1388.

Wickramanayake, T. W. \& Panabokke, R. (1961). The relation between diet and atherosclerosis in Ceylon. American Journal of Clinical Nutrition 9, 752-756.

Wilson, W. S., Hulley, S. E., Burrows, M. I. \& Nichaman, M. Z. (1971). Serum lipid and lipoprotein responses to the American Heart Association fat-controlled diet. American Journal of Medicine 51, 491. 